\title{
HIV drug remains unproven without placebo trial
}

\section{Ethical concerns over use of a placebo weaken evidence for the benefits of nevirapine.}

Sir — While raising concerns about

"standards of record keeping" in the HIVNET 012 trial in Uganda, in your News story "Activists and researchers rally behind AIDS drug for mothers" (Nature 432, 935; 2004), you overlook a greater flaw. None of the available evidence for nevirapine comes from a trial in which it was tested against a placebo. Yet, as the study's senior author has said (see www.hopkinsmedicine.org/hmn/ S01/feature.html), a placebo is the only way a scientist can assess a drug's effectiveness with scientific certainty.

The HIVNET 012 trial abandoned its placebo group in early 1998 after only 19 of the 645 mothers randomized had been treated, under pressure of complaints that the use of a placebo was unethical.

The HIV transmission rate reported for nevirapine in the HIVNET 012 study was $13.1 \%$. However, without antiretroviral treatments, mother-to-child transmission rates of HIV vary from $12 \%$ to $48 \%$.

The HIVNET 012 outcome is higher than the $12 \%$ transmission rate reported in a prospective study of 561 African women given no antiretroviral treatment (J. Ladner et al. J. Acquir. Immun. Def. Syndr. Hum. Retrovirol. 18, 293-298; 1998).

There are also reports of placebo-group transmission rates that vary within the same hospital and between hospitals, as well as during different time periods of the same study. One study reported a lower transmission rate in the placebo group than with no treatment.

On what basis can it be claimed that "there's nothing that has in any way invalidated the conclusion that singledose nevirapine is effective for reducing mother-to-child transmission"? Without supporting evidence from a placebocontrolled randomized trial, such statements seem unwarranted.

Valendar F. Turner

Department of Health, 189 Royal Street, East Perth, Western Australia 6004, Australia

\section{Concern over deep-sea} reefs is widespread

Sir - As a deep-sea biologist I was surprised to read the letter by Kjartan Hoydal from the North-East Atlantic Fisheries Commission (Nature 433, 105; 2005).

Contrary to Hoydal's contention that the News Feature "Sink or swim" (Nature $432,12-14$; 2004) reflects a campaign by a few scientists and non-governmental organizations, the scientific evidence that fisheries are a threat to newly discovered deep-sea habitats is well documented and has been acknowledged by several governments.

The concerns raised in your News Feature are shared by many deep-sea biologists: 1,136 scientists from 69 countries signed a recent petition to the United Nations on this issue. Many governments and international bodies also believe that bottom trawling and other fishing practices are causing significant damage to deep-sea habitats.

Deep-sea coral reefs have been known for 200 years or more, but our understanding of their potential contribution to marine biodiversity is more recent, owing to new technologies that allow direct imaging of the deep-sea floor. This technology has also provided graphic evidence of destruction of these habitats by bottom trawling.

For example, it is estimated that off Norway up to $50 \%$ of reefs, formed by the coral Lophelia pertusa, have already been affected by fishing. In the Northern Rockall Trough, northwest of Scotland, evidence of damage to coral has been seen both in video images and in acoustic pictures of the seabed.
The United Nations Environment Programme (UNEP) recently published a report by several world experts on deepsea coral reefs: Cold-water Coral Reefs: Out of Sight, No Longer out of Mind (UNEPWorld Conservation Monitoring Centre Biodiversity Series No. 22), available at www.unep-wcmc.org. The report states: "Undoubtedly, the greatest and most irreversible damage is due to the increasing intensity of deep-water trawling that relies on the deployment of heavy gear which 'steamrollers' over the sea floor."

This report was endorsed by environment ministers from several European nations. Because of quantitative evidence of trawling damage, the Norwegian government has banned bottom trawling from areas in which L. pertusa reefs occur. Measures have also been taken to protect L. pertusa in the northern Rockall Trough (European Commission Regulation no. 1475/2003).

The impacts of deep-sea trawling on coral reefs have been well documented in other parts of the world, including seas off Nova Scotia, the southern United States southern Australia.

I welcome the North-East Atlantic Fisheries Commission's recent move to protect some deep-sea habitats in the North Atlantic. However, the fishing industry has little awareness of the environmental damage caused by trawling and other fishing practices.

Sustainable management of the deep-ocean environment will require a substantial and joint effort by marine scientists, fisheries managers and the fishermen themselves.

Alex David Rogers

Natural Environment Research Council, British Antarctic Survey, High Cross, Madingley Road, Cambridge CB3 OET, UK

\section{Brown knew particles were smaller than pollen}

Sir - In your Year of Physics supplement (Nature 433, 213-257; 2005), several authors repeat the mistaken idea that the botanist Robert Brown observed the motion that now carries his name while watching the irregular motion of pollen grains in water. The microscopic particles involved in the characteristic jiggling dance Brown described were much smaller clay particles. I have regularly studied pollen grains in water suspension under a microscope without ever observing brownian motion.

From the title of Brown's 1828 paper "A Brief Account of Microscopical Observations ... on the Particles contained in the Pollen of Plants...", it is clear that he knew he was looking at smaller particles (which he estimated at about 1/500 of an inch in diameter) than the pollen grains.

Having observed 'vivid motion' in these particles, he next wondered if they were alive, as they had come from a living plant. So he looked at particles from pollen collected from old herbarium sheets (and so presumably dead) but also found the motion. He then looked at powdered fossil plant material and finally inanimate material, which all showed similar motion.

Brown's observations convinced him that life was not necessary for the movement of these microscopic particles. Brown was not the first to observe the motion that now carries his name and that Einstein famously explained. However, he was convinced his was the first really detailed study of the phenomenon and he clearly hoped for priority for his description.

David M. Wilkinson

Biological and Earth Sciences, Liverpool John Moores University, Byrom Street, Liverpool L3 3AF, UK 


\section{Immigration could ease climate-change impact}

\section{A modest proposal to allow the big gas-emitters to take their share of responsibility.}

Sir - The recent UN World Conference on Disaster Reduction in Kobe, Japan, was dominated by discussion of the Indian Ocean tsunami ("Solo efforts hamper tsunami warning system" Nature 433, 343; 2005). However, we must not forget the extreme vulnerability of small islands and low-lying coastal areas to sea-level rise caused by climate change.

The accumulation of greenhouse gases in the atmosphere during the past few hundred years is likely to result in a sealevel rise of up to half a metre, possibly more, by 2050 (R. J. Nicholls \& J. A. Lowe, Glob. Environ. Change, in the press). Many of the affected countries do not have the resources to adopt protective measures such as sea walls and embankments, nor can they afford insurance. By the end of the century, millions are likely to have been driven from their homes by sea-level rise.

One of the ironies of climate change is that, although wealthy countries are responsible for most of the accumulated greenhouse gases in the atmosphere, they will probably face less damage than poor countries. As climate negotiations 'beyond Kyoto' take shape, it is time to consider a framework wherein people living in areas likely to be rendered uninhabitable by climate change would have the early option of migrating elsewhere - specifically to those countries that are largely responsible.

The number of vulnerable 'climatechange exiles' received by a host country would be in approximate proportion to that country's cumulative greenhouse-gas emissions. Estimates suggest that roughly 50 million to 200 million people will be displaced by the 2080s, owing to the direct impacts of climate change under a plausible range of emissions scenarios (R. J. Nicholls Glob. Environ. Change 14, 69-86; 2004). Assuming that all these climate-change exiles are absorbed by the top ten 'emitter' countries, new annual immigrants would range from a few thousand for the Czech Republic to about three-quarters of a million for the United States.

Once the basic principle (which is consistent with Articles 1 and 4.8 of the United Nations Framework Convention on Climate Change) is accepted, there will be several ways to determine who should be considered for immigration benefits, which countries should bear the costs of immigration, and what institutional and political mechanisms are needed in order to minimize the risks of a massive refugee crisis as climate impacts become more severe.

Figuring out an international strategy to address the needs of these climatechange exiles will be easier now than later. Sujatha Byravan*, Sudhir Chella Rajan $\dagger$ *Council for Responsible Genetics, 5 Upland Road, Cambridge, Massachusetts 02140, USA $\dagger$ Tellus Institute, 11 Arlington Street, Boston, Massachusetts 02116, USA

\section{Consumer law is used to attack climate findings}

Sir - Your News story "Salt sellers challenge US health agency using dataquality act" (Nature 433, 671; 2005), suggests that a lawsuit filed by the Salt Institute represents "the first time that a petitioner has actually sued under the Data Quality Act". This is not the case, although the ruling that the Salt Institute is appealing was the first verdict given in a case brought under the federal Data Quality Act.

In August 2003 a conservative advocacy group, the Competitive Enterprise Institute, filed a suit claiming violations of the act against President George Bush and John Marburger, director of the White House Office of Science and Technology Policy (OSTP). The most important claim was that reports by the US National Assessment of the potential consequences of climate change (USNA) used results from two different global climate models to construct scenarios of future climate (see National Assessment Synthesis Team, Climate Change Impacts on the United States, Cambridge Univ. Press, Cambridge, 2000) — which therefore violated the act because one of the two scenarios had to be in error.

In November 2003, just as the Department of Justice was preparing to file its response, the parties accepted a ruling of "dismissal with prejudice", meaning that the lawsuit could not be refiled. Although the Department of Justice did not release its brief, it had apparently made a strong argument against the absurd notion that projections of the future must be proven accurate in advance.

The OSTP nonetheless ordered that a notice be added to USNA web pages, indicating that the reports "were not subjected to OSTP's Information Quality Act Guidelines". This implies that the USNA report was not properly reviewed and would not meet the OSTP guidelines. This is misleading at best, as the report was subjected to a four-stage review that was more comprehensive than called for by the act. In addition, the OSTP guidelines did not exist or apply at the time that the USNA was released.

Attempts by the USNA's lead authors and contributors (including myself) to get this notice removed or modified have failed, leaving in place an unfair criticism of the assessment's widely accepted findings. Michael C. MacCracken

Climate Institute, 1785 Massachusetts Avenue NW, Washington DC 20036, USA

\section{That chemist pose is a classic because we do it}

Sir - I note with some surprise that Philip Ball, in his Science in Culture article "What's in the flask?" (Nature 433, 17; 2005), says that gazing into a flask held aloft — as in the stereotypical image -

"is not what real chemists spend their time doing". As a synthetic organic chemist, I would like to point out that this is exactly what real chemists do.

My research group regularly observes the initiation of crystallization or precipitation in this fashion. Magnification through the curved walls of the flask, with the brightly lit background of the ceiling lighting, lets one see the changes in the morphology of small particles as they form (often at the liquid surface), while trying to avoid solutes crashing out of solution unselectively.

As chemistry is so often the glue connecting biology, physics and medicine in this interdisciplinary age, we can only hope that more people will discover what chemists actually do.

Piers R. J. Gaffney

Department of Chemistry, Imperial College, South Kensington Campus,

Exhibition Road, London SW7 2AZ, UK

Erratum In David M. Wilkinson's Correspondence letter "Brown knew particles were smaller than pollen" (Nature 434, 137; 2005), the sentence "The microscopic particles involved in the characteristic jiggling dance Brown described were much smaller clay particles" should not have contained the word "clay", which was added in error during the editing process. The particles Brown saw were inside the pollen grains.

\section{correspondence}

Contributions to Correspondence may be submitted to corres@nature.com. They should be no longer than 500 words, and ideally shorter. 